\title{
Establishing Allowable Value of Electric Conductivity for Monitoring Groundwater Based on the Benchmark Dose Concept and its Application
}

\author{
Hidenori Ito, Todd Saunders, Junya Miyamoto, Masaya Nishiyama and Tsuyoshi Nakamura \\ School of Engineering and Science \\ Nagasaki University \\ Nagasaki, Japan \\ hi-debow@kxa.biglobe.ne.jp.
}

\begin{abstract}
Recently, a number of studies have pointed out that Electric Conductivity (EC) would be a very effective measure for monitoring the quality of ground water possibly polluted by sewage sludge or incineration ash leachate. However, few have explicitly determined the allowable limit of the $E C$ value. Therefore, we have obtained the allowable limit of EC by applying the "benchmark dose (BMD)" method.
\end{abstract}

Keywords-component; Electric Conductivity; bench mark dose; environmental standard; sewage sludge; incineration ash; monitoring

\section{INTRODUCTION}

Increasing and improperly treated sewage sludge and poor disposal management are common problems facing large cities. This improper processing has helped to spread excessive pollutants into the environment. The classical composting of sludge is causing environmental degradation through concentrated organic matter, nitrogen, inorganic salts, heavy metals, and bacteria contamination in the soil [1]. As a result, incineration has recently increased, also requiring safe and efficient ash disposal techniques. Groundwater contamination, caused by low quality processing of sewage sludge and incineration ash, is regarded as a serious problem demanding a cost effective method for its monitoring. Recently a number of reports have proposed Electrical Conductivity (EC) as an effective technique to monitor pollutants [2, 3]. Few however, have clearly determined the allowable limit of the EC value for groundwater polluted by sewage sludge leachate or incinerator ash.

In this study, we use the "benchmark dose" (BMD) approach [4], which was originally developed to determine the allowable or tolerable limit of exposure to such contaminants as dioxin, $\mathrm{Cd}$, and $\mathrm{Hg}$ to obtain an allowable limit of EC, and have subsequently applied this value to several actual cases.

\section{METHODS}

\section{A. Background and Data}

The study area is "Sanpou" Mountain located just east of Nagasaki city. There is a final disposal plant atop the mountain and a few homes and farms below. The plant started operation in 1975 and had dumped and buried sewage sludge, incinerated ash and industrial waste on to and into the surrounding land heedless of any established standards or regulations, before a law prohibiting this dumping was enforced. Nagasaki City Hall also buried undocumented miscellaneous waste generated by a severe flood. The accumulation of this waste has now polluted groundwater flowing under the plant.

In 1997, water quality test data was falsified by Nagasaki City Hall, and some citizens filed a criminal complaint with Nagasaki City and the Plant for possible illegal disposal techniques. This affair prompted Nagasaki City Hall to perform a detailed survey of the contamination in the soil and the groundwater around the repository site in 1998 and 1999. The site (Fig. 1) is on a southeast facing 15 degree decline with the sewage sludge disposal area shaded green, the industrial waste area shaded blue, and sludge and waste areas shaded pink. A concrete containment tank filled with industrial waste and incinerated ash was leaking at site No.5. Groundwater movement flowed in the direction of the arrows in Fig. 1, and was confirmed by salt tracers. Sites No.2 and No.4 are considered to be contaminated by the sewage sludge, and site No.3 by the incineration ash. Site No.1 is in a national forest where human activity is prohibited and more importantly not in the same aquifer as the treatment plant. This pristine region was set as a natural control area considered free of human origin contamination.

Environmental standard values, or limits of allowable values, are necessary for the effective use of EC by civil services for groundwater quality control. An environmental standard is a threshold value, set as a result of risk assessment of reliable data and made with sound scientific knowledge for the management of human health, safety and security, for potentially harmful agents under specified circumstances. The environmental standard for $\mathrm{NO}_{3}-\mathrm{N}$ is currently set at $10 \mathrm{mg} / \mathrm{l}$. There is not however a standard for EC. 


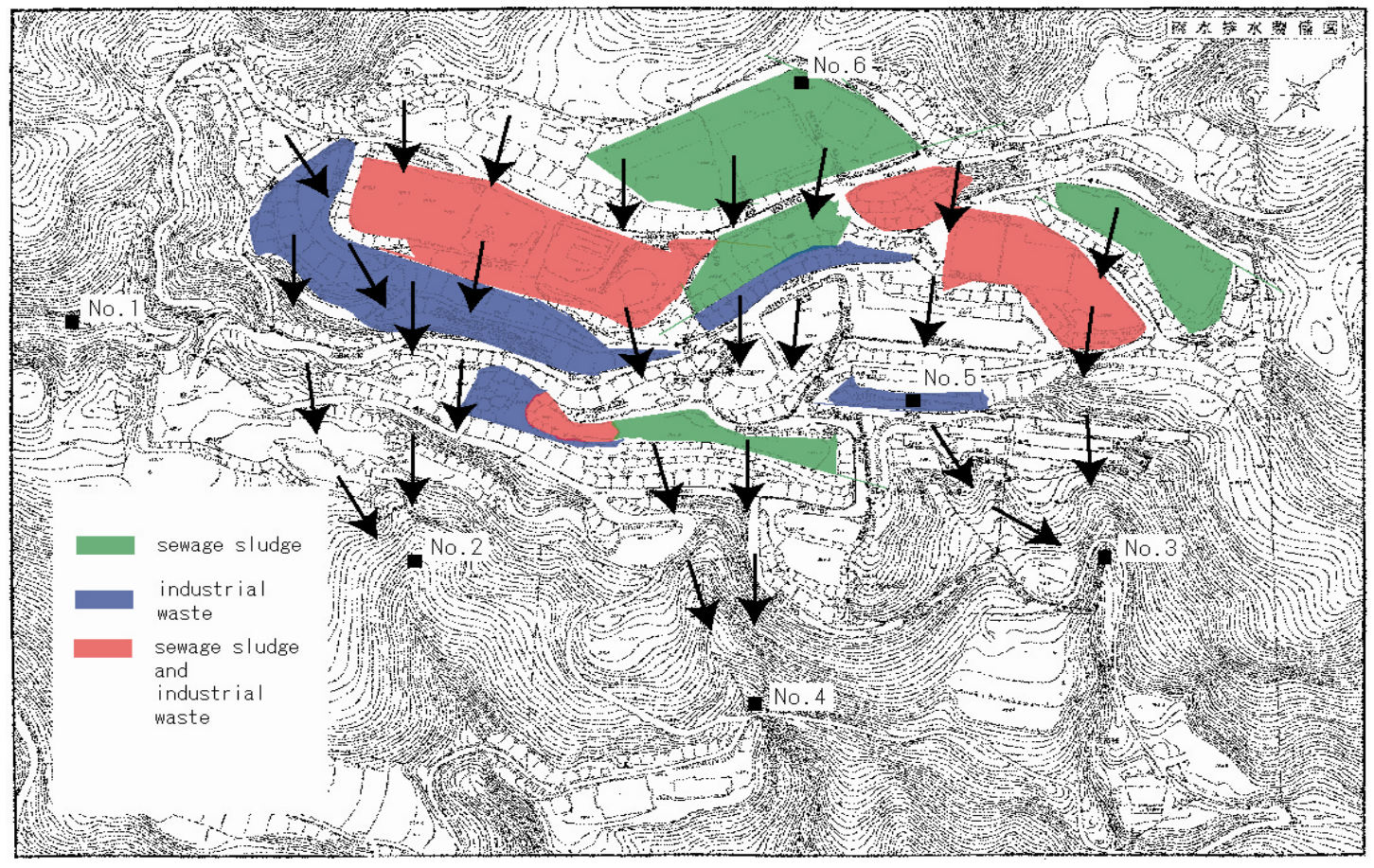

Figure 1. Study site overview with groundwater flow direction $(\rightarrow)$, boring points (No. $1 \sim 4$ ) and dumping sites.

\section{B. NOAEL/LOAEL and BMD}

In an early literature, cancer risk was determined by fitting an appropriate dose-response model to bioassay data to estimate risks over the entire range of exposure. Then the dose of an exposure that will result in a pre-specified limit of risk is estimated using a linear extrapolation of risks at observed doses to the origin. This method was criticized because of a lack of validation and uncertainty in the extrapolation. Later, the NOAEL/ LOAEL (Non-Observed Adverse Effect Level/ Lowest Observed Adverse Effect Level) approach came into practice. However, it was also criticized for not using all of the data and the standard value determined heavily depended on the sample size as well as
The most notable of the alternatives is the benchmark dose (BMD) suggested by Crump [2]. The BMD is defined as the lower $95 \%$ confidence bound on dose which results in some pre-specified level of risk. Various organizations and regulatory agencies in the US and abroad have considered adoption of its use [6]. The BMD approach is being considered in the international arena as part of the effort to develop a standard approach [3,7]. In general, BMD is determined by fitting a dose-response model to data observed in the range of higher doses, or higher risk doses, since it is difficult to observe responses in low doses. Murrell et al define a modified BMD for making comparison among various endpoints more meaningful [5]. On the other hand,

TABLE I. SUMMARY OF WATER QUALITY TESTS FOR 10 YEARS (FOUR TIMES A YEAR) BY SITE.

\begin{tabular}{ccccccc}
\hline $\mathrm{No} .1$ & $\mathrm{pH}$ & $\mathrm{Cl}^{-}(\mathrm{mg} / \mathrm{l})$ & $\mathrm{EC}(\mathrm{mS} / \mathrm{m})$ & $\mathrm{NO}_{3}-\mathrm{N}(\mathrm{mg} / \mathrm{l})$ & $\mathrm{SO}_{4}{ }^{2-}(\mathrm{mg} / \mathrm{l})$ & $\mathrm{T}\left({ }^{\circ} \mathrm{C}\right)$ \\
\hline avg & 5.71 & 9.30 & 8.19 & 4.38 & 2.29 & 15.37 \\
$\mathrm{SD}$ & 0.30 & 1.06 & 0.79 & 1.00 & 1.71 & 2.56 \\
$\mathrm{max}$ & 6.9 & 11.6 & 9.9 & 6.76 & 12.2 & 28.5 \\
$\min$ & 5.3 & 7.7 & 6.8 & 2.63 & 1 & 12.5 \\
\hline \hline $\mathrm{No} .2$ & $\mathrm{pH}$ & $\mathrm{Cl}^{-}(\mathrm{mg} / \mathrm{l})$ & $\mathrm{EC}(\mathrm{mS} / \mathrm{m})$ & $\mathrm{NO}_{3}-\mathrm{N}(\mathrm{mg} / \mathrm{l})$ & $\mathrm{SO}_{4}{ }^{2-}(\mathrm{mg} / \mathrm{l})$ & $\mathrm{T}\left({ }^{\circ} \mathrm{C}\right)$ \\
\hline avg & 6.59 & 70.18 & 41.57 & 11.78 & 18.66 & 16.19 \\
$\mathrm{SD}$ & 0.19 & 4.74 & 3.14 & 2.10 & 5.84 & 0.75 \\
$\max$ & 7.1 & 82.8 & 48.2 & 15.2 & 29.8 & 20.2 \\
$\min$ & 6.3 & 56.7 & 36.4 & 5.23 & 7 & 15 \\
\hline
\end{tabular}

\begin{tabular}{ccccccc}
\hline $\mathrm{No} .3$ & $\mathrm{pH}$ & $\mathrm{Cl}^{-}(\mathrm{mg} / \mathrm{l})$ & $\mathrm{EC}(\mathrm{mS} / \mathrm{m})$ & $\mathrm{NO}_{3}-\mathrm{N}(\mathrm{mg} / \mathrm{l})$ & $\mathrm{SO}_{4}{ }^{2-}(\mathrm{mg} / \mathrm{l})$ & $\mathrm{T}\left({ }^{\circ} \mathrm{C}\right)$ \\
\hline avg & 6.68 & 46.01 & 26.83 & 2.56 & 2.92 & 16.63 \\
$\mathrm{SD}$ & 0.13 & 3.95 & 3.13 & 0.78 & 3.19 & 0.43 \\
$\max$ & 6.9 & 53 & 32.2 & 5.07 & 22 & 17.7 \\
$\min$ & 6.3 & 37 & 21.6 & 1.41 & 1.4 & 15.4 \\
\hline \hline $\mathrm{No} 4$ & $\mathrm{pH}$ & $\mathrm{Cl}^{-}(\mathrm{mg} / \mathrm{l})$ & $\mathrm{EC}(\mathrm{mS} / \mathrm{m})$ & $\mathrm{NO}_{3}-\mathrm{N}(\mathrm{mg} / \mathrm{l})$ & $\mathrm{SO}_{4}{ }^{2-}(\mathrm{mg} / \mathrm{l})$ & $\mathrm{T}\left({ }^{\circ} \mathrm{C}\right)$ \\
\hline avg & 6.18 & 121.44 & 64.5 & 14.12 & 25.97 & 16.88 \\
$\mathrm{SD}$ & 0.22 & 17.87 & 3.25 & 1.30 & 14.79 & 0.34 \\
$\max$ & 6.6 & 148 & 70.9 & 16.1 & 75.7 & 17.8 \\
$\min$ & 5.6 & 61.8 & 58.7 & 10.5 & 3.5 & 16.1 \\
\hline
\end{tabular}

the study design [5]. That is, the response to a low dose not being statistically significant may be due to a small sample size or an inappropriate model

Sand et al illustrate an epidemiological approach for a continuous response variable based on the definition of the normal range for clinical data [7]. When developing water 
quality standards, the latter approach seems appropriate for use with our data to show relationships between $\mathrm{NO}_{3}-\mathrm{N}$ and EC, under pristine and uncontaminated environmental conditions, with regards to the standard value of 10 for $\mathrm{NO}_{3}$ $\mathrm{N}$ as a pre-specified limit of risk.

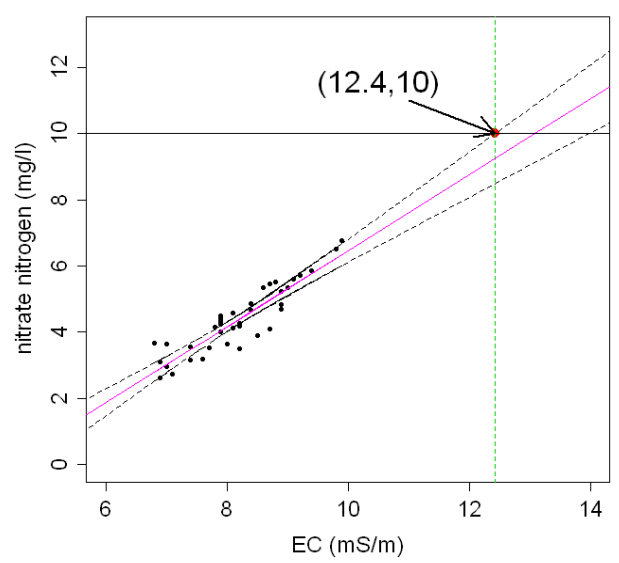

Figure 2. Scatter plot of EC vs. NO3-N. The linear regression line with $95 \%$ confidence band is shown. 12.4 is determined to be the BMD.

\section{RESULTS}

Table I summarizes the results of water quality tests performed four times a year between 1998 2008 for each site. No. 1 is the control site. $86 \%$ and $100 \%$ of $\mathrm{NO}_{3}-\mathrm{N}$ measurements for sites No. 2 and No. 4, respectively, exceeded the standard value 10 , whereas site No. 3 is high in $\mathrm{Cl}$ but low in $\mathrm{NO}_{3}-\mathrm{N}$, which is typical of incinerated ash leachate.

There is a strong linear relationship between $\mathrm{EC}$ and $\mathrm{NO}_{3}-\mathrm{N}$ at site No. 1 (Fig. 2). The variation in $\mathrm{NO}_{3}-\mathrm{N}$ at site No. 1 is possibly due to fluctuations in the amount of rain or fallen leaves caused by seasonal changes, unrelated to human activity. This demonstrates the relationship between $\mathrm{NO}_{3}-\mathrm{N}$ and EC under undisturbed natural conditions. We analyzed these relationships to apply BMD to determine an allowable EC limit of $12.4 \mathrm{mS} / \mathrm{m}$ for monitoring groundwater possibly contaminated by sewage sludge and incinerated ash.

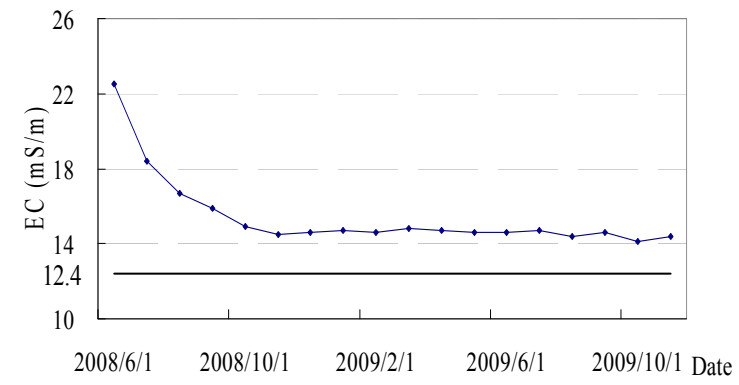

Figure 3. Longitudinal EC values of a groundwater at No. 6 where monitoring was ordered by the court.

\section{APPLICATION}

If we apply the BMD EC value of 12.4 as an environment standard value, City Hall could order the plant to apply clean up measures for the groundwater at site No. 3, where $\mathrm{NO}_{3}-\mathrm{N}$ is under 10 but $\mathrm{Cl}$ is high due to incineration ash buried around site No. 5 .

It was recently pointed out that the groundwater at site No.6 may be contaminated by sewage sludge and the plant has started monitoring the site. Monitoring of this site allows for the continuous measuring of EC, but not EC and $\mathrm{NO}_{3}-\mathrm{N}$ simultaneously. The $\mathrm{EC}$ values were constantly over 13 as shown in Fig. 3. But, since there is no allowable limit of EC in the current regulations, our request for a detailed examination of the groundwater was denied by the plant for a year and a half. When we demonstrated that the observed EC value indicated an $\mathrm{NO}_{3}-\mathrm{N}$ value over 10 , the allowable limit, based on the $\mathrm{BMD}$ value, and $\mathrm{NO}_{3}-\mathrm{N}$ was subsequently measured between 11 and 14 in the following months, The Environmental Administrative Office directed the plant to take some purification measures based on environmental protection laws.

The standards set forth by this study are expected to have an impact on the development of environmental regulations for groundwater contamination in Japan.

\section{DISCUSSION}

These results indicate human-origin contamination when EC measurements are over 12.4 in the monitoring of groundwater. If the cause of the pollution is sewage sludge or excess compost, $\mathrm{NO}_{3}-\mathrm{N}$ is likely to exceed the standard value of 10. High amounts of $\mathrm{Cl}$ associated with incinerated ash leachate may also cause the EC to exceed 10. Therefore, any accurate water quality test done with EC should mandate 12.4 as the standard value for identifying contamination. From a preventive point of view, EC values should be measured frequently so that any trend approaching 12.4 may be detected and preventative measures can be enacted.

EC tests are required for the monitoring of waste repositories in Japan, and the EC measurement device used for this monitoring is inexpensive, easy-to-use and presents 
precise measurements. The effects of setting an environmental standard for EC measurements of groundwater at 12.4 are undeniable and will greatly help in correctly identifying contaminated sites.

Performing meta-analysis of BMD values independently calculated from data observed at some sites will be useful in determining a standard value widely and effectively applicable for groundwater conservation.

\section{REFERENCES}

[1] P. Vasanthi, S. Kaliappan, R. Srinivasaraghavan, "Impact of poor solid waste management on ground water," Environ. Monit. Assess, vol. 143, pp. 227-238, 2008.

[2] M. Nagamori, Y. Watanabe, T. Hase, Y. Kurata, Y. Ono, K. Kawamura, "A simple and convenient empirical survey method with a soil electrical conductivity meter for incineration residue-derived soil contamination," J. Mater. Cycles Waste Manag, vol. 9, pp. 90-98, 2007.

[3] Z. Ahad, A. Qadir, "Source evaluation of physicochemically contaminated groundwater of Dera Ismail Khan area, Pakistan. Environ,” Monit. Assess, pp. 1-13, 2010.

[4] K. Crump, "A new method for determining allowable daily intakes," Fundam. Appl. Toxicol, vol. 4, pp. 854-871, 1984.

[5] J. A. Murrell, C. J. Portier, R. W. Morris, "Characterizing DoseResponse I: Critical Assessment of the Benchmark Dose Concept," Risk Analysis, vol. 18, pp. 13-26, 1998.

[6] U.S. Environmental Protection Agency (USEPA). The benchmark dose software version 1.3.2. Available at: http://cfpub.epa.gov/ncea/, 2007.

[7] S. Sand, K. Victorin, A. F. Filipsson, "The current state of knowledge on the use of the benchmark dose concept in risk assessment," J. Appl. Toxicol, vol. 28, pp. 495-421, 2008. 